OPEN ACCESS

Edited by: James Donald Fortenberry,

Emory University, USA

Reviewed by:

Pradip P. Kamat,

Emory University, USA

Gail Mary Annich,

The Hospital for Sick Children,

Canada

*Correspondence:

Aitt A. Sarnaik

asarnai@med.wayne.edu

Specialty section:

This article was submitted to

Pediatric Critical Care,

a section of the journal

Frontiers in Pediatrics

Received: 26 May 2016 Accepted: 17 August 2016 Published: 30 August 2016

Citation:

Valentine KM, Sarnaik $A A$, Sandhu HS and Sarnaik AP (2016) High Frequency Jet Ventilation in

Respiratory Failure Secondary to Respiratory Syncytial Virus Infection:

A Case Series.

Front. Pediatr. 4:92.

doi: 10.3389/fped.2016.00092

\section{High Frequency Jet Ventilation in Respiratory Failure Secondary to Respiratory Syncytial Virus Infection: A Case Series}

\author{
Kevin M. Valentine ${ }^{1}$, Ajit A. Sarnaik ${ }^{2 *}$, Hitesh S. Sandhu ${ }^{3}$ and Ashok P. Sarnaik ${ }^{2}$ \\ 'Section of Critical Care, Department of Pediatrics, Riley Hospital for Children, Indiana University, Indianapolis, IN, USA, \\ 2Department of Pediatrics, Critical Care Division, Children's Hospital of Michigan, Wayne State University, Detroit, MI, USA, \\ ${ }^{3}$ Department of Pediatrics, Critical Care Division, Le Bonheur Children's Hospital, University of Tennessee, \\ Memphis, TN, USA
}

Objective: To describe the utility of high frequency jet ventilation (HFJV) as a rescue therapy in patients with respiratory failure secondary to respiratory syncytial virus (RSV) that was refractory to conventional mechanical ventilation (CMV).

Design: Descriptive study by retrospective review.

Setting: Pediatric intensive care unit at a tertiary care children's hospital.

Patients: Infants on mechanical ventilation for respiratory failure due to RSV.

Interventions: Use of HFJV.

Main Results: Eleven patients were placed on HFJV. There was sustained improvement in ventilation on HFJV with a mean decrease in $\mathrm{PCO}_{2}$ of $9 \mathrm{mmHg}$ at $24 \mathrm{~h}$ and $11 \mathrm{mmHg}$ at $72 \mathrm{~h}$. There were no significant changes in oxygenation by oxygenation index. No patients required extracorporeal support or suffered pneumothorax, pneumomediastinum, or subcutaneous emphysema. Ten out of 11 (91\%) patients survived to discharge from the hospital.

Conclusion: High frequency jet ventilation may represent an alternative therapy for RSVinduced respiratory failure that is refractory to CMV.

Keywords: respiratory insufficiency, respiratory acidosis, respiratory syncytial virus, high frequency ventilation, high frequency jet ventilation, bronchiolitis

\section{INTRODUCTION}

Respiratory syncytial virus (RSV) is one of the most common causes of lower respiratory tract infection in children worldwide, causing a substantial disease burden. In a large population-based study in the USA, RSV bronchiolitis was responsible for $22-24 \%$ of outpatient visits and an estimated $75,000-125,000$ annual hospital admissions in the USA (1). Of hospitalized children with RSVrelated illness, approximately $10-20 \%$ require critical care due to acute respiratory insufficiency and require admission to the pediatric intensive care unit (PICU) with intubation and mechanical 
ventilation (2). About $5 \%$ of intubated patients require more support than conventional ventilation can provide.

Ventilation index (VI), which takes into account $\mathrm{PaCO}_{2}$ in relation to respiratory support, has been correlated with an increased risk of death in children with acute respiratory failure, and it has been proposed that alternative modalities be sought when VI is greater than 65 (3). In these patients, the use of rescue therapies such as high frequency oscillatory ventilation (HFOV) and extracorporeal membranous oxygenation (ECMO) has been advocated (4-6). Patient characteristics associated with more severe disease and adverse outcomes include prematurity, young age, chromosomal abnormalities, cardiac disease, and neuromuscular disease $(1,5,6)$.

Infants with respiratory failure from RSV can present with diverse clinical presentations characterized by distinct pathophysiology. Some patients primarily exhibit increased lower airway resistance with airway edema, mucus plugging, and dynamic hyperinflation. Other patients primarily exhibit a disease of decreased static compliance similar to acute respiratory distress syndrome (ARDS), with alveolar disease, decreased functional residual capacity, and intrapulmonary shunting $(7,8)$. Infants who develop ARDS from RSV are more likely to be younger and have premorbid conditions such as prematurity, congenital heart disease, and immunodeficiency compared to those who have more obstructive disease (7).

High frequency jet ventilation (HFJV) has been described in patients with air leak/bronchopleural fistula (9), in infants with pulmonary interstitial emphysema (10), and ARDS (11, 12). We report our single institution experience with HFJV in RSV respiratory failure with severe derangements in oxygenation and ventilation not responding to conventional mechanical ventilation (CMV).

\section{MATERIALS AND METHODS}

A list of intubated children with RSV who were treated with HFJV from October 2010 through May 2012 was obtained from the Virtual PICU database (Virtual PICU Systems, LLC). In these patients with clinical bronchiolitis, RSV was confirmed by rapid antigen test or PCR from respiratory tract secretions.

Medical records were retrospectively examined for the following data: age of patient, premorbid conditions, sex, weight, days of illness, indication for intubation, peak conventional ventilator settings, arterial or capillary blood gases before and after the initiation of HFJV, and HFJV settings. Total time spent on each mode of mechanical ventilation was calculated and any additional or rescue therapies to improve ventilation, such as airway lavage with or without bronchoscopy and the use of heliox were documented. Full conventional mechanical ventilator support was defined as tidal volume of $7-9 \mathrm{~mL} / \mathrm{kg}$ with minimum set rate of 26 breaths per minute. The VI was calculated as [respiratory rate $\left.\times(\mathrm{PIP}-\mathrm{PEEP}) \times \mathrm{PCO}_{2}\right] / 1000$.

This study was approved by the Institutional Review Board at Wayne State University School of Medicine and Detroit Medical Center.

\section{Inclusion/Exclusion Criteria}

Patients were included if they had RSV bronchiolitis and transitioned to HFJV from CMV. Reasons for the patients to be transitioned from CMV to HFJV were categorized as: (a) hypercapnic respiratory failure if patients had a PIP greater than $35 \mathrm{cmH} 2 \mathrm{O}$ for more than $6 \mathrm{~h}$ associated with persistent respiratory acidosis $\left(\mathrm{pH} \leq 7.25, \mathrm{PCO}_{2}>60 \mathrm{mmHg}\right.$ ) or (b) hypoxemic respiratory failure with ARDS as defined by Berlin criteria (13).

\section{Ventilation Strategy}

All intubated RSV patients were managed with pressure-controlled, synchronized intermittent mandatory ventilation (SIMV) as the initial ventilation mode. Puritan Bennett 840 (Covidien, Mansfield, MA, USA), Hamilton G-5 (Reno, NV, USA) and E vent-Inspiration 5i (San Clemente, CA, USA) were used for mechanical ventilation.

High frequency jet ventilation was delivered by Life Pulse HFJV (Bunnell Inc., Salt Lake City, UT, USA) in tandem with a conventional ventilator. HFJV settings were chosen with an initial $\mathrm{FiO}_{2}$ of 1.0 , and a rate of $360-420$ per minute with an inspiratory time of $0.02 \mathrm{sec}$. Peak inflation pressure was initiated at $40 \mathrm{cmH}_{2} \mathrm{O}$ and titrated based on $\mathrm{PCO}_{2}$ clearance. The PEEP of the conventional ventilator functions as the source for the mean airway pressure (MAP) of the system and was titrated to achieve a MAP 2-3 $\mathrm{cmH}_{2} \mathrm{O}$ higher than the MAP on conventional ventilation prior to initiating HFJV. A beginning rate of five conventional ventilator breaths per minute was titrated down to zero as MAP was optimized (see http://www.bunl.com/technical. html for diagram of HFJV setup).

\section{Statistical Analysis}

For descriptive statistics, categorical variables are presented using absolute counts and percentage. Continuous variables are presented using medians and range. Bivariate correlations were performed with continuous data and Spearman's correlation with ordinal data. Comparisons conducted between variables were done with related-samples Wilcoxon Signed Rank test. Adverse event data are reported using raw numbers, percentages, and ratios. SPSS version 21.0 was utilized for analyses; $p<0.05$ was considered to be significant.

\section{RESULTS}

During the time frame of evaluation, there were 75 patients admitted with RSV-related respiratory failure. Eleven patients met the inclusion criteria for the study; all had community acquired RSV. One patient received 2 courses of HFJV, thus constituting a total of 12 courses. Baseline characteristics and brief clinical summaries of the patients are presented in Table 1 . Nine out of the 11 patients were prematurely born, and 3 were on oxygen at baseline. One patient had trisomy 21 with an unrepaired ventricular septal defect. Only one subject was a previously healthy, full-term infant. Two patients initially met criteria for mild ARDS while the other nine met criteria for moderate to severe ARDS based on the 2012 Berlin definition (13). 
TABLE 1 | Patient characteristics and clinical course summary.

\begin{tabular}{|c|c|c|c|c|c|c|c|c|c|}
\hline Pt & $\begin{array}{c}\text { Age } \\
\text { (wks) }\end{array}$ & $\begin{array}{l}\text { Wt } \\
(\mathrm{kg})\end{array}$ & Comorbid & $\mathbf{V} \mathbf{l}^{\mathbf{a}}$ & $\mathrm{Ol}^{\mathrm{a}}$ & $\begin{array}{l}\text { HFJV } \\
\text { days }\end{array}$ & $\begin{array}{l}\text { MV } \\
\text { days }\end{array}$ & $\begin{array}{l}\text { ICU } \\
\text { days }\end{array}$ & Other clinical events \\
\hline 1 & 26 & 2.4 & $\begin{array}{l}\text { 24-week premature female, } \\
\text { home oxygen }\end{array}$ & 132 & 32 & 7 & 19 & 27 & Bronchoscopies (4), surfactant, no complications, survived \\
\hline 2 & 2 & 1.7 & $\begin{array}{l}\text { 35-week premature male, } \\
\text { chronic lung disease }\end{array}$ & 54 & 20 & 7 & 24 & 33 & iNO, bronchoscopies (2), no complications, survived \\
\hline 3 & 3 & 4.7 & Previously healthy female & 71 & 7 & 4 & 7 & 8 & No complications, survived \\
\hline 4 & 156 & 14.2 & 26-week premature male & b & 12 & 7 & 9 & 14 & $\begin{array}{l}\mathrm{PCO}_{2} \text { at the time of HFJV initiation } 92 \mathrm{mmHg} \text {. No } \\
\text { complications, survived }\end{array}$ \\
\hline $\begin{array}{l}5.1 \\
5.2\end{array}$ & 13 & 4.2 & $\begin{array}{l}\text { 34-week premature male, } \\
\text { home oxygen for first } \\
6 \text { weeks of life }\end{array}$ & $\begin{array}{l}52 \\
85\end{array}$ & $\begin{array}{r}11 \\
8\end{array}$ & $\begin{array}{l}1 \\
5\end{array}$ & $\begin{array}{l}23 \\
23\end{array}$ & $\begin{array}{l}32 \\
32\end{array}$ & $\begin{array}{l}\text { 1st HFJV course: HFJV } 1 \text { day discontinued for hypercarbia, } \\
\text { received heliox and surfactant. 2nd HFJV course: HFJV } \\
5 \text { days, bronchoscopies (3). Subglottic stenosis, survived }\end{array}$ \\
\hline 6 & 8 & 4.8 & 36-week premature male & 52 & 11 & 1 & 5 & 6 & No complications, survived \\
\hline 7 & 4 & 3.0 & 34-week premature male & 62 & 12 & 6 & 13 & 16 & No complications, survived \\
\hline 8 & 8 & 4.4 & $\begin{array}{l}\text { 34-week premature female, } \\
\text { liver abscess }\end{array}$ & $\mathrm{b}$ & 37 & 9 & 24 & 30 & $\begin{array}{l}\mathrm{PCO}_{2} \text { at HFJV initiation } 71 \mathrm{mmHg} \text {. Inotropes, } \\
\text { bronchoscopies (2), no complications, survived }\end{array}$ \\
\hline 9 & 4 & 2.9 & $\begin{array}{l}\text { Trisomy } 21 \text {, VSD, 35-week } \\
\text { premature female }\end{array}$ & 33 & 14 & 10 & 17 & 37 & Bronchoscopy once, no complications, survived \\
\hline 10 & 3 & 4 & $\begin{array}{l}\text { 31-week premature female, } \\
\text { on home oxygen }\end{array}$ & 40 & 17 & 6 & 11 & 13 & Bronchoscopies (2), no complications, survived \\
\hline 11 & 26 & 4.7 & $\begin{array}{l}\text { 24-week premature female, } \\
\text { on MV first } 4 \text { months of life, } \\
\text { on home oxygen }\end{array}$ & b & 28 & 2 & 10 & 12 & $\begin{array}{l}\text { Pre-HFJV on HFOV for ARDS, pneumothorax, surfactant. } \\
\text { HFJV } 2 \text { days with worsening ARDS. On inotropes, multiple } \\
\text { organ failure, died }\end{array}$ \\
\hline
\end{tabular}

${ }^{a} \mathrm{VI}$ and OI calculated at time of HFJV initiation where data available.

${ }^{b}$ Conventional mechanical ventilation data not available to calculate VI at baseline for patients 4, 8, and 11.

For all 12 courses, HFJV was used as a rescue therapy for ventilatory failure with hypoxia and/or hypercapnia refractory to CMV. The pre-HFJV VI was available for nine patients. The mean and median VI were 65 and 54, respectively (range of 33-132). All subjects had hypercapnic respiratory failure defined as an elevated $\mathrm{PCO}_{2}$ with respiratory acidosis despite full conventional mechanical support. Other therapies used in the clinical care of these patients are presented in Table 2. Of note, no patient received preventative RSV immune globulin despite the eligibility of all but one patient.

The mean $\mathrm{PCO}_{2}$ before HFJV initiation was $72 \mathrm{mmHg}$ (range $57-102 \mathrm{mmHg}$ ), and decreased from baseline by $9 \mathrm{mmHg}$ at $24 \mathrm{~h}, 12 \mathrm{mmHg}$ at $48 \mathrm{~h}(p=0.018)$, and $11 \mathrm{mmHg}$ at $72 \mathrm{~h} \mathrm{after}$ starting HFJV. Figure 1 shows individual patients as well as the mean $\mathrm{PCO}_{2}$ over time. The mean and median oxygenation index (OI) before starting HFJV were 17 and 14, respectively (range 5-32). The mean and median OI at $72 \mathrm{~h}$ were both 12 (range 2-24). There was no significant change in OI over this time frame.

None of the patients received ECMO. There were no complications of pneumothorax, pneumomediastinum, or subcutaneous emphysema associated with HFJV in this cohort. One patient developed subglottic stenosis. One patient died.

\section{DISCUSSION}

In patients with severe respiratory failure refractory to CMV, rescue therapies have been described, such as HFOV and ECMO
TABLE 2 | Therapies ( $n=12$ HFJV courses); data are absolute counts (\%).

\begin{tabular}{ll}
\hline Inhaled nitric oxide & $2(17)$ \\
Heliox & $1(8)$ \\
Mucolytic therapy & $3(25)$ \\
Surfactant & $3(25)$ \\
Palivizumab (Synagis ${ }^{\mathrm{P}}$ ) & $0(0)$ \\
Systemic corticosteroids & $0(0)$ \\
ECMO & $0(0)$ \\
Antibiotics & $6(50)$ \\
Bronchoalveolar lavage & $7(58)$
\end{tabular}

(14-17). However, ECMO carries considerable morbidity and mortality. According to a query of the Extracorporeal Life Support (ELSO) registry from 1993 to 2007, the mortality of children who required ECMO for RSV pneumonia was 30\%, and the mortality of children with chronic lung disease who required ECMO for respiratory failure was $41 \%$ (18). In addition to the risk of morbidity and mortality, an ECMO program requires substantial resources, expertise, and surgical support. Although a case report and small case series $(16,19,20)$ describe the use of HFOV in obstructive airway disease, the use of HFOV in patients with severe obstruction to airflow has the potential to worsen air trapping and hyperinflation and may be considered a contraindication for use (21).

The pathophysiology of pediatric respiratory failure from RSV can be represented by a polarized clinical spectrum. One end of the spectrum is airway obstruction caused by bronchiolitis, which is characterized by airway edema, bronchial and bronchiolar 


\section{PCO2 on HFJV}

\section{0}

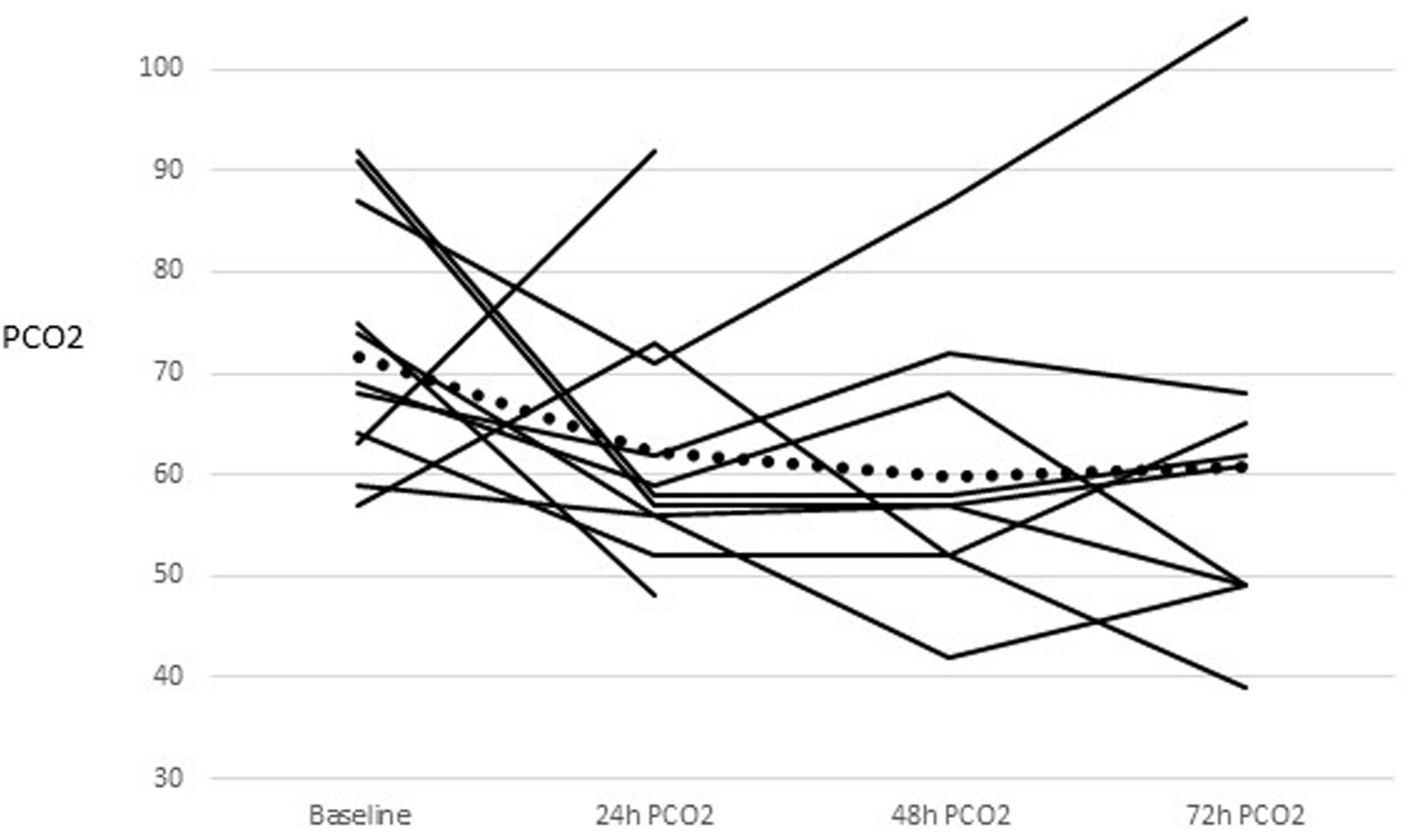

FIGURE $1 \mid \mathbf{P C O}_{2}$ change for each individual and the combined mean after HFJV initiation. The combined means are represented as the dotted line.

obstruction, and mucus plugging. This can lead to wheezing, prolonged and incomplete exhalation with air trapping and auto- or intrinsic PEEP as well as radiographic evidence of hyperinflation. The other end of the spectrum of respiratory failure from RSV is pneumonitis characterized by pathophysiology similar to ARDS. This is manifested by edema and inflammation of the alveoli and pulmonary interstitium resulting in reduced compliance (7). The resulting atelectasis and multifocal airspace disease lead to intrapulmonary shunting, ventilation-perfusion mismatch, and hypoxemia. Although the clinical manifestations of RSV lower respiratory tract disease in any given patient can overlap, many patients exhibit a predominance of either obstructive or restrictive lung disease causing respiratory failure.

Maintenance of adequate FRC in patients with pneumonia/ ARDS manifestations and avoidance of auto-PEEP and airtrapping in those with obstructive airways are major challenges. In some children, CMV fails to improve oxygenation/ventilation, and rescue therapies such as high frequency ventilation and ECMO are sought. If the outcomes were similar, HFV would be preferable to ECMO because of the less invasive nature and less technical support needed for implementation and management.

In such patients, HFJV offers certain theoretical advantages compared to HFOV. The equal pressure point (EPP) where intrathoracic pressure during exhalation is equal to intraluminal pressure, is shifted distally (toward the alveoli) in diseases characterized by airway obstruction such as RSV bronchiolitis (22). The active expiration of HFOV creates negative pressure in the proximal airway that may not be uniformly dissipated distally because of prolonged time constant due to increased resistance. This leads to excessive transmural pressure resulting in proximal airway collapse, further increase in airway resistance, and air trapping. Transmural pressure favoring proximal airway collapse also occurs with the use of HFJV, but its magnitude is expected to be much less compared to that of HFOV because exhalation is passive and intraluminal pressure remains positive throughout exhalation (Figure 2).

High frequency jet ventilation offers some advantages in pulmonary hygiene over HFOV. Suctioning the airway may be done by way of an inline suction catheter with HFJV while the system is often opened for suctioning on HFOV, potentially resulting in alveolar derecruitment. Additionally, the physics of gas exchange peculiar to HFJV are beneficial in removing airway debris and in management of hyperinflation, both of which cause physiologic derangement in respiratory failure from RSV. HFJV delivers short pulses of high velocity inspired gas described as "transitional flow," which preferentially travels much faster through the center of the airways where the drag is less. In RSV, these pulses of inspired air move past secretions coating the airways. 

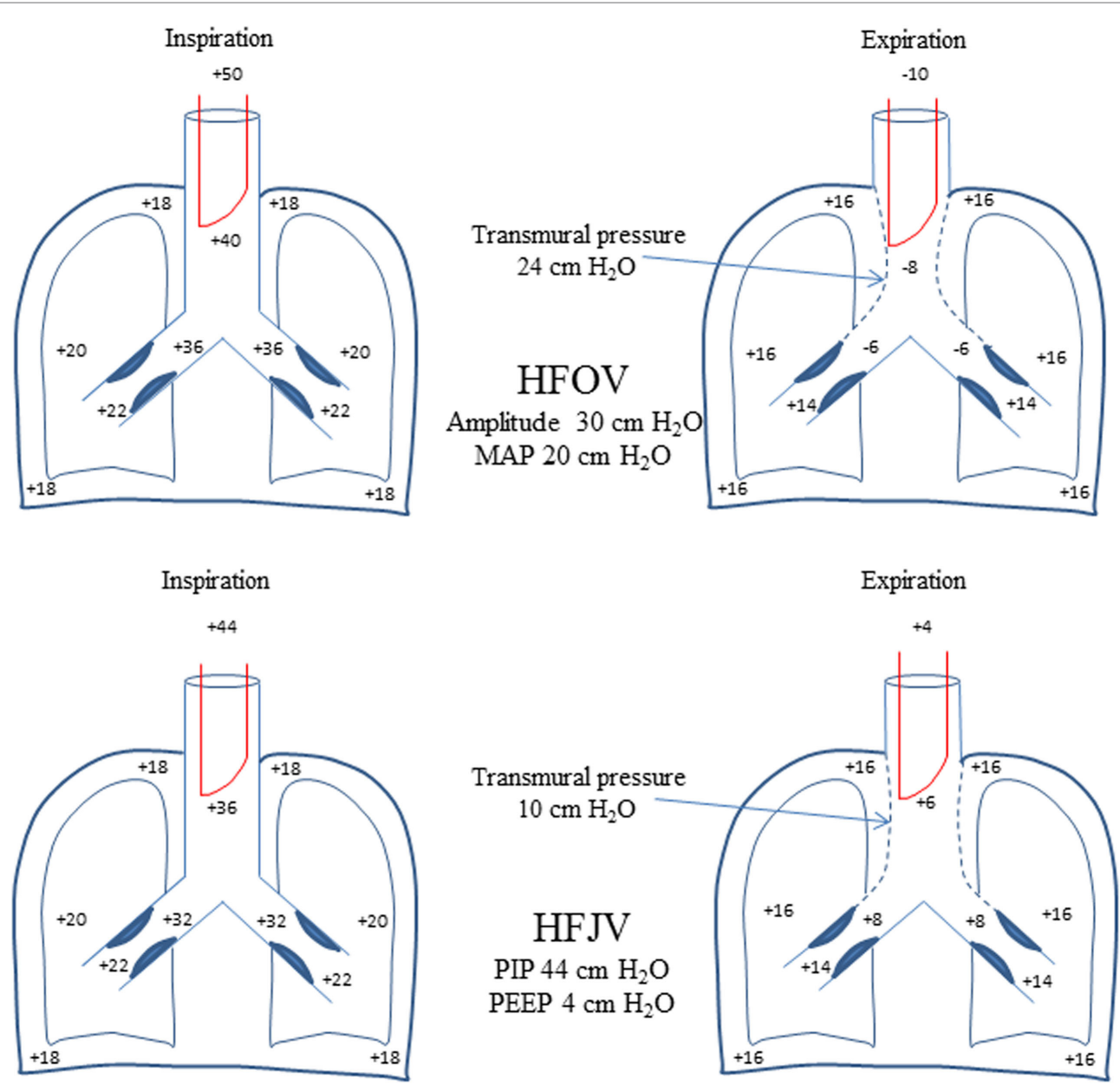

FIGURE 2 | Schematic comparison with theoretical pressures reflecting dynamic changes in airway caliber during HFOV and HFJV. The active exhalation of HFOV with negative intraluminal pressure is expected to result in greater increase in transmural pressure compared with passive exhalation of HFJV where intraluminal pressure remains positive throughout exhalation. This would lead to greater collapse of the proximal airway and higher expiratory resistance and air trapping especially in an obstructive disease (such as RSV bronchiolitis) in HFOV compared with HFJV. Transmural pressure equals intrapleural pressure minus airway (alveolar) pressure. See text for further explanation.

The slower-moving exhaled gas spirals around the outer aspects of the airway, contributing to augmented removal of airway debris. This is consistent with previous reports describing the use of HFJV to augment the mobilization of obstructing casts in plastic bronchitis (23), and to remove debris in meconium aspiration (24).

The cohort of subjects in the present study represents the more severe spectrum of respiratory failure from RSV. Of 75 mechanically ventilated patients with acute respiratory failure from RSV infection, 11 were ill enough to be considered for rescue therapy. Nine of these 11 patients had pre-existing chronic lung disease of prematurity, which carries higher risk of mortality. Five patients had bronchopulmonary dysplasia, four of them being on supplemental oxygen at home. Three patients had a VI $\geq 70$; one patient had an OI $\geq 32$ prior to the initiation of HFJV. These patients represent the extremes of acute hypercapnic and hypoxic respiratory failure for whom extracorporeal support would be a reasonable option. They were successfully supported with HFJV until such time as they were able to be weaned off mechanical respiratory support. One patient developed subglottic stenosis, the other nine recovered to their pre-illness baseline for respiratory support. One patient in our study died, and that patient was deemed a poor candidate for ECMO due to pre-existing severe, chronic lung disease and prolonged cardiopulmonary arrest prior to arrival to the hospital.

Limitations of this study include the retrospective nature, small sample size, and lack of uniformity in HFJV management. However, the significance of these exploratory findings is the relative success of HFJV as an alternative treatment for severe ventilatory failure from RSV.

\section{CONCLUSION}

This case series describes the utility of HFJV as an alternative, rescue therapy for RSV-induced respiratory failure that is refractory to CMV. HFJV was tolerated by this group of patients without 
evidence of new/worsened chronic lung disease. The utility of HFJV should be further explored in this patient population as an alternative therapy for severe, refractory ventilatory failure.

\section{AUTHOR CONTRIBUTIONS}

Dr. KV contributed to study design, data collection, data analysis, and the majority of the manuscript preparation. Dr. AAS contributed to study design, data analysis, preparation of the tables, and part of the manuscript preparation and revision. Dr. HS

\section{REFERENCES}

1. Hall CB, Weinberg GA, Iwane MK, Blumkin AK, Edwards KM, Staat MA, et al. The burden of respiratory syncytial virus infection in young children. N Engl J Med (2009) 360(6):588-98. doi:10.1056/NEJMoa0804877

2. Prodhan P, Sharoor-Karni S, Lin J, Noviski N. Predictors of respiratory failure among previously healthy children with respiratory syncytial virus infection. Am J Emerg Med (2011) 29(2):168-73. doi:10.1016/j. ajem.2009.08.020

3. Paret G, Ziv T, Barzilai A, Ben-Abraham R, Vardi A, Manisterski Y, et al. Ventilation index and outcome in children with acute respiratory distress syndrome. Pediatr Pulmonol (1998) 26(2):125-8. doi:10.1002/ (SICI) 1099-0496(199808)26:2<125::AID-PPUL9>3.0.CO;2-L

4. Flamant C, Hallalel F, Nolent P, Chevalier JY, Renolleau S. Severe respiratory syncytial virus bronchiolitis in children: from short mechanical ventilation to extracorporeal membrane oxygenation. Eur J Pediatr (2005) 164(2):93-8. doi:10.1007/s00431-004-1580-0

5. Berger TM, Aebi C, Duppenthaler A, Stocker M, Swiss Pediatric Surveillance Unit. Prospective population-based study of RSV-related intermediate care and intensive care unit admissions in Switzerland over a 4-year period (2001-2005). Infection (2009) 37(2):109-16. doi:10.1007/ s15010-008-8130-z

6. Thorburn K. Pre-existing disease is associated with a significantly higher risk of death in severe respiratory syncytial virus infection. Arch Dis Child (2009) 94(2):99-103. doi:10.1136/adc.2008.139188

7. Hammer J, Numa A, Newth CJ. Acute respiratory distress syndrome caused by respiratory syncytial virus. Pediatr Pulmonol (1997) 23(3):176-83. doi:10.1002/(SICI) 1099-0496(199703)23:3<176::AID-PPUL2>3.0.CO;2-M

8. Roe M, O'Donnell DR, Tasker RC. Respiratory viruses in the intensive care unit. Paediatr Respir Rev (2003) 4(3):166-71. doi:10.1016/S1526-0542(03)00056-3

9. Roth MD, Wright JW, Bellamy PE. Gas flow through a bronchopleural fistula. Measuring the effects of high-frequency jet ventilation and chest-tube suction. Chest (1988) 93(1):210-3. doi:10.1378/chest.93.1.210

10. Keszler M, Donn SM, Bucciarelli RL, Alverson DC, Hart M, Lunyong V, et al. Multicenter controlled trial comparing high-frequency jet ventilation and conventional mechanical ventilation in newborn infants with pulmonary interstitial emphysema. J Pediatr (1991) 119(1 Pt 1):85-93. doi:10.1016/ S0022-3476(05)81046-7

11. Sarnaik AP, Meert KL, Pappas MD, Simpson PM, Lieh-Lai MW, Heidemann SM. Predicting outcome in children with severe acute respiratory failure treated with high-frequency ventilation. Crit Care Med (1996) 24(8):1396-402. doi:10.1097/00003246-199608000-00020

12. Keszler M, Modanlou HD, Brudno DS, Clark FI, Cohen RS, Ryan RM, et al. Multicenter controlled clinical trial of high-frequency jet ventilation in preterm infants with uncomplicated respiratory distress syndrome. Pediatrics (1997) 100(4):593-9. doi:10.1542/peds.100.4.593

13. ARDS Definition Task Force, Ranieri VM, Rubenfeld GD, Thompson BT, Ferguson ND, Caldwell E, et al. Acute respiratory distress syndrome: the Berlin definition. JAMA (2012) 307(23):2526-33. doi:10.1001/jama.2012.5669

14. Thompson MW, Bates JN, Klein JM. Treatment of respiratory failure in an infant with bronchopulmonary dysplasia infected with respiratory syncytial contributed to study design, data collection, and manuscript revision. Dr. APS contributed to study design, data analysis, preparation of the figures, and part of the manuscript preparation and revision.

\section{ACKNOWLEDGMENTS}

All work was performed at Children's Hospital of Michigan, Detroit, MI, USA. This manuscript is reported with approval from Wayne State University's Institutional Review Board.

virus using inhaled nitric oxide and high frequency ventilation. Acta Paediatr (1995) 84(1):100-2. doi:10.1111/j.1651-2227.1995.tb13497.x

15. Medbo S, Finne PH, Hansen TW. Respiratory syncytial virus pneumonia ventilated with high-frequency oscillatory ventilation. Acta Paediatr (1997) 86(7):766-8. doi:10.1111/j.1651-2227.1997.tb08584.x

16. Duval EL, Leroy PL, Gemke RJ, van Vught AJ. High-frequency oscillatory ventilation in RSV bronchiolitis patients. Respir Med (1999) 93(6):435-40. doi:10.1053/rmed.1999.0578

17. Berner ME, Hanquinet S, Rimensberger PC. High frequency oscillatory ventilation for respiratory failure due to RSV bronchiolitis. Intensive Care Med (2008) 34(9):1698-702. doi:10.1007/s00134-008-1151-3

18. Zabrocki LA, Brogan TV, Statler KD, Poss WB, Rollins MD, Bratton SL. Extracorporeal membrane oxygenation for pediatric respiratory failure: survival and predictors of mortality. Crit Care Med (2011) 39(2):364-70. doi:10.1097/CCM.0b013e3181fb7b35

19. Duval EL, van Vught AJ. Status asthmaticus treated by high-frequency oscillatory ventilation. Pediatr Pulmonol (2000) 30(4):350-3. doi:10.1002/1099-0496(200010)30:4<350::AID-PPUL13>3.0.CO;2-2

20. Frerichs I, Achtzehn U, Pechmann A, Pulletz S, Schmidt EW, Quintel M, et al. High-frequency oscillatory ventilation in patients with acute exacerbation of chronic obstructive pulmonary disease. J Crit Care (2012) 27(2):172-81. doi:10.1016/j.jcrc.2011.04.008

21. Fessler HE, Derdak S, Ferguson ND, Hager DN, Kacmarek RM, Thompson BT, et al. A protocol for high-frequency oscillatory ventilation in adults: results from a roundtable discussion. Crit Care Med (2007) 35(7):1649-54. doi:10.1097/01.CCM.0000269026.40739.2E

22. West JB, editor. Mechanics of breathing. 8th ed. Respiratory Physiology - The Essentials. Philadelphia: Lippincott Williams and Wilkins (2008). p. 95-122.

23. Zahorec M, Kovacikova L, Martanovic P, Skrak P, Kunovsky P. The use of high-frequency jet ventilation for removal of obstructing casts in patients with plastic bronchitis. Pediatr Crit Care Med (2009) 10(3):e34-6. doi:10.1097/ PCC.0b013e3181a334ba

24. Sevecova-Mokra D, Calkovska A, Drgova A, Javorka M, Javorka K. Treatment of experimental meconium aspiration syndrome with surfactant lung lavage and conventional vs. asymmetric high-frequency jet ventilation. Pediatr Pulmonol (2004) 38(4):285-91. doi:10.1002/ppul.20081

Conflict of Interest Statement: The authors declare that the research was conducted in the absence of any commercial or financial relationships that could be construed as a potential conflict of interest.

The reviewer PK and handling Editor declared their shared affiliation, and the handling Editor states that the process nevertheless met the standards of a fair and objective review.

Copyright $(02016$ Valentine, Sarnaik, Sandhu and Sarnaik. This is an open-access article distributed under the terms of the Creative Commons Attribution License (CC BY). The use, distribution or reproduction in other forums is permitted, provided the original author(s) or licensor are credited and that the original publication in this journal is cited, in accordance with accepted academic practice. No use, distribution or reproduction is permitted which does not comply with these terms. 